\title{
História e Filosofia das Ciências no contexto escolar pós-moderno: uma contribuição ao ensino de ciências a partir da hermenêutica filosófica de Gadamer
}

Deyvid José Souza Santos ${ }^{1}$

Mestrando do Programa de Pós-Graduação em Ensino de Ciências e

Matemática - UNIFESP

Diadema - SP

Thaís Cyrino de Mello Forato ${ }^{1}$

José Alves da Silval

Departamento de Ciências Exatas e da Terra - UNIFESP

Diadema - SP

\section{Resumo}

Com o objetivo de contribuir para o processo de formação de adolescentes nas nossas escolas, este artigo levanta algumas reflexões sobre possibilidades para a abordagem da História e Filosofia das Ciências no contexto escolar pós-moderno. Apresentamos a hermenêutica filosófica de Gadamer como um campo de estudos que pode auxiliar o diálogo entre esses temas, fundamentando a elaboração de propostas para o ensino de ciências. Nesse sentido, enfatizamos sua potencialidade para ajudar professoras e professores a lidarem com o problema do subjetivismo, com concepções relativistas ingênuas sobre as Ciências e para criticarem ou combaterem o negacionismo científico, visto que ela nos mostra que é possivel entendermos o quanto a razão é fundamental nos processos de intelecção sobre o mundo natural, justamente quando levamos em conta os aspectos históricos e sociológicos que abarcam o nosso processo de compreensão. Dentro desse contexto, indicamos a necessidade de uma educação e formação de professores e professoras que ajude a lidar com os sentimentos, a formação do caráter, o desejo de autorrealização e com o exercício de

\footnotetext{
${ }^{+}$History and Philosophy of Science in the scholar postmodern context: a contribution to sciences education from Gadamer's hermeneutics

* Recebido: 30 de julho de 2020. Aceito: 21 de dezembro de 2020.

1'E-mail: deyvid.jose@unifesp.br; thais.forato@unifesp.br; josealves.unifesp@gmail.com
} 
uma ética da razão cordial, a qual inclua as exigências universais de justiça e os valores morais que inspiram uma sociedade autenticamente democrática, tal como é proposto pela filósofa espanhola Adela Cortina. Levando em conta a revisão bibliográfica realizada sobre esses temas, levantamos alguns questionamentos ao longo do artigo e no final apresentamos três argumentos que são indicativos da potencialidade da hermenêutica filosófica de Gadamer ajudar a implementar a História e Filosofia das Ciências no ensino de ciências. Do resultado da nossa reflexão, também percebemos o quanto os usos da História e Filosofia das Ciências na sala de aula podem tornar-se ainda mais relevantes e enriquecedores caso sejam levados em consideração aspectos de adolescência na pós-modernidade.

Palavras-chave: Hermenêutica; História e Filosofia das Ciências; Formação de Professores(as); Pós-Modernidade; Adolescência.

\begin{abstract}
In order to contribute to the educational background of adolescents in our schools, this paper raises some reflections on the post-modern school context and the History and Philosophy of Science. Presenting Gadamer's hermeneutics as a study field that can facilitate the dialogue between these themes and to help on elaboration of proposals for sciences teaching. In this sense, we emphasize its potential to help teachers to deal with the problem of relativism and subjectivism in sciences education and to criticize or to combat scientific negationism, since it shows us that it is possible to understand how much the reason is fundamental precisely when we take into account the historical and sociological aspects that comprise our understanding process. Within this context, we indicate the need of a teacher educational background that helps to deal with feelings, character formation, self-realization desire and the exercise of a cordial reason ethics, that is, including the universals of justice and the moral values that inspired an authentically democratic society, as adopted by the Spanish philosopher Adela Cortina. Taking into account the bibliographic review carried out on these themes, we raised some questions throughout the article and at the end we present three arguments that are indicative of the potential of Gadamer's hermeneutics to help implement the history and philosophy of science in science teaching. From the result of our reflection, we also realized how much the use of History and Philosophy of Science in the
\end{abstract}


classroom can become even more fundamental and enriching if aspects of adolescence in postmodernity are considered.

Keywords: Hermeneutics; History and Philosophy of Science; Teachers' Education; Postmodern; Adolescence.

\section{Nossos pontos de partida}

Pensar sobre abordagens da História e Filosofia das Ciências (HFC) no ensino requer considerarmos os pressupostos implícitos nessa interpretação do passado, nos relatos construídos e nas concepções filosóficas que daí podem emergir. O fazer historiográfico, sendo ele próprio contextualizado, revela valores e retrata pressões sociais e políticas de uma época, dados que não podem ser ignorados. Quando falamos em historiografia das ciências, podemos admitir, por exemplo, que o passado e o presente se constituem e se relacionam de maneira complexa, formando uma rede de influências que muda ao longo do tempo (MARTINS, R., 2010). Assumir isso implica no reconhecimento de que o historiador trabalha a partir de uma seleção das diferentes circunstâncias que podem ser estudadas em dado momento histórico, o que lhe permite criar uma ordem compreensível a esse conjunto de eventos por meio de uma narrativa histórica, a qual inevitavelmente mostrará seus valores, crenças e preconcepções. Nesse sentido, aqui consideramos que:

Não é possivel uma narrativa histórica totalmente neutra; mas pode-se deixar explícito, para o leitor, que se trata de um resumo de uma história mais complexa, e que a seleção e as conexões apresentadas são fruto da mente do historiador. (MARTINS, R., 2010, p. 7).

Daí decorre a relevância de se compreender o contexto em que se dá a construção de uma narrativa historiográfica, assim como a importância de se buscarem diferentes interpretações de um mesmo evento ou de um episódio da história das ciências.

Uma visão mais rica do passado vai sendo construída quando são levados em consideração diferentes enfoques que exploram aspectos epistêmicos e não epistêmicos de um mesmo episódio, os quais abarcam diversas variáveis que contribuíram para a aceitação de determinada teoria pela comunidade científica, como os contextos social, político e econômico em que ela se desenvolveu. Robilotta (1988), por exemplo, destaca o valor do conhecimento extraído da experiência e da indução, mas defende que a física não se limita a tais aspectos, e adiciona que não são apenas fatores considerados racionais e objetivos que permeiam o desenvolvimento da ciência, havendo também elementos subjetivos, dentre outros, que nos ajudam a compreender o fenômeno:

No que diz respeito à objetividade da observação, muitos exemplos extraídos tanto da história da ciência como da psicologia experimental mostram que os processos 
de percepção e observação dependem fortemente da cultura em que se dão e da socialização dos indivíduos (ROBILOTTA, 1988, p. 14).

Ademais, conforme apontam Forato et. al (2011), ao levarmos em consideração esses outros aspectos, é preciso destacar a pluralidade metodológica ao longo da história das ciências, trazendo também elementos ligados à historicidade dos sujeitos (psicológicos, axiológicos, morais, etc.), mas exemplificando os critérios de cientificidade aceitos em cada época, de forma a contrabalancear uma possível interpretação extrema de relativismos acerca das ciências, algo que poderia ser bastante nocivo, principalmente no contexto atual de recrudescimentos de falsas verdades, pós-verdade, negacionismos e fake news. Na segunda década do século XXI, por exemplo, assistimos nas redes sociais a argumentos de grupos explicitamente anticientíficos, que consideram as ciências como geradoras de teorias errôneas ou mesmo de caráter conspiratório diante de determinadas disputas ideológicas, enquadrandose neste movimento grupos terraplanistas e antivacinas (ALBUQUERQUE; QUINAN, 2019; VASCONCELOS; LARA, 2019).

Dessa forma, nos indagamos: como desenvolver, em tal contexto, uma visão crítica das ciências que incorpora também aspectos sociológicos? As professoras e professores de ciências estariam arriscando o futuro desenvolvimento das ciências ao tentarem mostrar que elas acontecem dentro de uma rede mais complexa do que os manuais e livros didáticos costumam apresentar?

Para responderem a essas perguntas, diferentes enfoques para a HFC no ensino de ciências têm sido propostos, assim como há muitas análises de seus desafios e potencialidades (p. ex. BAGDONAS; ZANETIC; GURGEL, 2018; BRAGA et al., 2012; CARVALHO; REIS, 2020; FORATO, 2018; JARDIM; GUERRA, 2017; LIMA, I., 2019; MARTINS, A., 2015; MOURA; GUERRA, 2016; OLIVEIRA; DRUMMOND, 2015; SCHIMIEDECKE; PORTO, 2014; SILVEIRA; PEDUZZI, 2014; VASCONCELOS; FORATO, 2018). Entendese que tais abordagens podem ajudar na compreensão das ideias científicas e das influências sofridas e exercidas por elas no desenvolvimento humano. Além disso, permitem mostrar que a ciência não se desenvolve apenas a partir da objetividade, do empirismo e da racionalidade de alguns heróis ou gênios. A ciência é uma herança de diferentes povos e culturas (MARTINS, 2006; ZANETIC, 2006). Nesse sentido, a utilização de episódios históricos pode evidenciar esse aspecto, além de mediar discussões sobre objetivismo e subjetivismo capazes de trazer à tona aspectos da natureza da ciência (NDC), que "é considerada um dos preceitos fundamentais para a formação de alunos e professores mais críticos e integrados com o mundo e a realidade em que vivem." (MOURA, 2014, p. 32).

Dentro dessa perspectiva crítica, é fundamental considerarmos o atual contexto sócio histórico em que estamos imersos e como a nossa realidade educacional se configura nesse momento. Com efeito, entendemos que essa realidade e o sujeito-aluno-adolescente devem ser considerados nos pressupostos, nas abordagens, nas formas e nos objetivos de ensinarmos conceitos científicos para nossos(as) estudantes. 
As condições sócio-culturais atuais, que se manifestaram desde o capitalismo pósindustrial, constituem a pós-modernidade, na qual se reconhece a insuficiência do modelo de razão iluminista para abarcar a realidade (BAUMAN, 1998; HABERMAS, 2002; NOVAIS, 2016). Esses estudos apontam para uma série de características específicas do nosso contexto atual, tais como o relativismo de valores outrora considerados inegociáveis, o surgimento de identidades fragmentadas, o questionamento e a desvalorização de costumes, regras e valores sociais historicamente construídos (BAUMAN, 1998), a exacerbação do narcisismo e a consequente manifestação de sentimentos de vazio interior ${ }^{2}$ (LIPOVETSKY, 2005), da vida como um absurdo e do surgimento de transtornos na subjetivização que se revelam na incapacidade de os sujeitos sentirem as pessoas e o mundo a sua volta (DUNKER, 2017; LIMA, J., 2019).

Essas características da pós-modernidade estão sendo levadas em consideração em contextos escolares e, de acordo com alguns pesquisadores e pesquisadoras, quando trazidas à tona, fica evidente a necessidade de mudanças de natureza pedagógica, conforme sugere Silva (2008):

Assim, às escolas cujos desafios historicamente são bastante complexos, acrescentase a necessidade de ir na contramão dos valores difundidos socialmente, nesse momento talvez mais do que em tempos anteriores. É preciso destacar a importância da coletividade em detrimento do individualismo; da reflexão em detrimento da "ação por si mesma"; da concentração em detrimento do processo de constante excitação; da valorização da dedicação em detrimento do prazer imediato; de certa revalorização da tradição em detrimento do culto à novidade; além da necessidade de se ter, em muitos casos, disciplina para se conseguir determinados objetivos (p. 50).

Assim, levando em conta a complexidade de nossos condicionamentos e a necessidade da escola ir na contramão de alguns valores que são difundidos socialmente na sociedade pós-moderna, consideramos que a implementação da HFC pode ser ainda mais valorizada e factível caso também se fundamente em algumas ideias da hermenêutica filosófica proposta pelo filósofo alemão Hans-Georg Gadamer (1900-2002), pois ela, tal qual os críticos da pós-modernidade (BAUMAN, 1998; HABERMAS, 2002; LIPOVESTKY, 2005), reconhece a insuficiência do modelo de razão iluminista para compreender a realidade, admite a influência da nossa historicidade para a compreensão e o diálogo com o mundo e propõe uma mediação entre razão e tradição.

Dentro dessa perspectiva, Luiz Carlos Bombassaro (1992) considera a racionalidade e a historicidade como a base do que é intrinsecamente humano e discute o quanto essas

\footnotetext{
${ }^{2}$ As perturbações narcísicas apresentam-se menos sob a forma de "perturbações com sintomas nítidos e bem definidos" do que sob a forma de "perturbações do caráter", caracterizadas por um mal-estar difuso e invasor, um sentimento de vazio interior e de absurdo da vida, uma incapacidade de sentir as coisas e os seres. (LIPOVETSKY, 2005, p. 56).
} 
categorias se mostram indissociáveis quando buscamos compreender a produção do conhecimento científico.

Em ressonância com tais ideias, a filósofa espanhola Adela Cortina (1947) defende que apenas a racionalidade pura não é suficiente para promover o senso de justiça e que, por conta disso, é necessário levar em consideração, nos processos de ensino-aprendizagem, aspectos afetivos que promovam a empatia, o sentimento de carinho, de compaixão, de apreço e de admiração que podem se constituir como a base para a promoção da justiça social, ajudando a promover um sentimento de pertencimento a uma cultura ou a uma tradição (OLIVEIRA; QUEIROZ, 2017). Nessa perspectiva, reconhecemos que para levar a sério os valores que inspiram uma sociedade democrática, não basta simplesmente desenvolvermos habilidades técnicas nos(as) jovens educandos(as), mas uma educação impregnada de valores morais que leve em conta, também, seus sentimentos e a busca pela autonomia e autorrealização de cada aprendiz.

\footnotetext{
Mas o certo é que é impossível construir uma sociedade autenticamente democrática contando apenas com indivíduos técnica e socialmente capacitados, porque tal sociedade precisa fundamentar-se em valores para os quais a razão instrumental é cega, valores como a autonomia e a solidariedade, que compõem de forma inevitável a consciência racional das instituições democráticas. Se o que queremos realmente é que o resultado do processo educativo seja um modelo de pessoa que só busca seu próprio bem-estar, então é suficiente uma razão baseada na racionalidade instrumental, que é a que rege a aquisição de habilidades técnicas. Mas se buscamos a formação de pessoas autônomas com desejo de autorrealização, então é necessária uma educação moral, no mais amplo sentido da palavra "moral" (CORTINA; MARTINEZ, 2015; p. 170, grifo dos autores).
}

Diante de toda essa conjuntura, se é verdade que as características da pósmodernidade nos atingem a todos, também é apontado um maior impacto juntamente aos adolescentes, conforme discutimos a seguir.

\section{Adolescência e pós-modernidade no contexto escolar}

Embora não exista um consenso acerca do que é adolescência, de início podemos associá-la a uma fase da vida (PEREIRA, 2005), marcada por diversas transformações, as quais envolvem tanto fatores cerebrais e hormonais (HERCULANO-HOUZEL, 2013) como psicológicos e afetivos (PEREIRA, 2005; GUTIERRA, 2003), trazendo à tona inúmeras dificuldades, tais como o questionamento a valores herdados dos pais e a necessidade do sujeito buscar autonomia e controle de suas próprias decisões (AMARAL, 2006; SILVA, 
2008). Tais ideias são comuns a pesquisadores de adolescência de diferentes áreas, desde a psicanálise até à neurociência ${ }^{3}$.

Pereira (2005), em seus estudos sobre a obra de Erickson (1902-1994), que discute as crises de identidade na adolescência, explica que este:

\section{(...) é um periodo de dificuldades para o jovem e para sua família. Os adolescentes buscam ativamente a autonomia, a independência e um senso de controle de suas próprias vidas, defendendo tudo aquilo que lhes pertence, incluindo sua maneira de pensar. É uma época de definição da personalidade, na qual o modelo de perfeição dos pais é desconstruído (p. 81).}

Dentro dessa perspectiva, também podemos destacar a necessidade dos(as) adolescentes construírem novas amizades e de participar de grupos, os quais podem permitir tanto uma expressão e apropriação de novos julgamentos, valores e informações sobre o mundo que os(as) cerca como impactar ou reforçar fatores como a popularidade, o prestígio e a aceitação diante de determinados grupos com os quais os(as) adolescentes convivem (OLIVEIRA, 2018).

Em seu trabalho 'Compromisso e paixão: o universal e o singular na boa escola pública', Silva (2008) afirma que os(as) adolescentes formam um verdadeiro mosaico de tipos e identidades e, juntamente com outros autores (AMARAL, 2006; CALIGARIS, 2000; PEREIRA, 2005; GUTIERRA, 2003), define a adolescência como uma etapa da vida que começa por volta dos 11 anos e que é marcada por mudanças físicas e o despertar da sexualidade voltada ao outro. No entanto, esclarece que ela não tem exatamente uma idade precisa para acabar, mas que costuma ser finalizada quando o sujeito adquire autonomia emocional e profissional. O mesmo autor aponta que, nessa fase da vida, o indivíduo manifesta diversas características, tais como a necessidade de referências, a mudança na convivência e no comportamento em grupos, a maximização de sentimentos e a negação das figuras tradicionais (como os pais). Em vista disso, neste trabalho adotamos a perspectiva de que a adolescência é uma construção histórica e cultural, relativamente recente na história da humanidade, e não restrita a mudanças físicas no corpo dos sujeitos (ÁRIES, 1981).

Essa forma de compreender a adolescência, que enfatiza a crise de identidade como fator central desse período, fica ainda mais agudizada quando levamos em consideração a questão identitária na pós-modernidade, conforme aponta Novais (2016):

(...) a questão mais importante da pós-modernidade é a mudança da visão de identidade. O sujeito do Iluminismo estava baseado numa concepção de indivíduo totalmente centrado, unificado, coerente, controlado, indivisível, dotado das

\footnotetext{
${ }^{3}$ A neurocientista Herculano-Houzel (2013), por exemplo, explica que na adolescência o cérebro infantil passa por sucessivas alterações que vão, aos poucos, transformando-os em um cérebro adulto, nos esclarecendo que o hipotálamo é responsável por ajustes fisiológicos no corpo que se relacionam diretamente com a ação de alguns hormônios (como a leptina) e que influenciam em algumas das mudanças percebidas nessa fase da vida.
} 
capacidades de razão e consciência. Na pós-modernidade, as velhas identidades estáveis e monolíticas dão lugar a identidades fragmentadas e não fixas, compostas não de uma, mas de várias identidades, plurais, dinâmicas, híbridas, difusas, fragmentadas, flexiveis e muitas vezes contraditórias (p. 120).

Tal panorama vai ao encontro do trabalho de Amaral (2011) acerca do enfraquecimento das noções de tradição e de autoridade na cultura ocidental e que cita Hannah Arendt para mostrar que o problema da falta de consolidação das identidades e da desvalorização do passado e da ancestralidade causa uma lacuna entre o passado e o presente, o que pode impactar em mudanças profundas na formação das subjetividades (que se tornam efêmeras porque aligeiradas), nas coletividades (a falta de sentimento de pertencimento gera mais individualizações), na organização familiar, nas escolas e, até mesmo, ameaça a conservação do patrimônio cultural da humanidade (posto que há uma desvalorização de tudo o que é considerado tradição, havendo uma supremacia e um verdadeiro culto a tudo o que é novo). E isso, segundo a mesma autora, afeta brutalmente a educação dos(as) adolescentes no contexto escolar:

É preciso observar, ainda, em que medida o campo de relações entre os agentes educativos (diretor, orientadores pedagógicos, professores e os alunos) se tomou palco de transferências (conscientes e inconscientes) de um complicado sistema de relações sociais (familiares e institucionais) cada vez mais esvaziadas de substância e de qualidade do vínculo, que se encontra, por sua vez, atravessado de um lado, por lógicas binárias no domínio da moralidade (separando de modo doutrinário o que é certo, o que é errado, o bem do mal etc.), induzindo a condutas mais ligadas à repressão do que à prevenção; e de outro, por uma espécie de desertificação da vida interior, que atinge professores e alunos, acompanhando o declinio da experiência e da narrativa e que tem atingido o seu ápice diante da crescente tendência neo-individualista do mundo contemporâneo. Uma tendência que tem induzido à liberação de todo compromisso social e de toda moral, associada com a liquidação da ideia de sacrificio (e do estímulo aos prazeres imediatos, ao culto do eu, da felicidade intimista e materialista), promovendo, ao mesmo tempo, a cultura dos direitos subjetivos (a obrigação existe apenas para consigo mesmo) (p. 80).

Aqui vemos a importância da proposta de Cortina e Martínez (2015) acerca de uma educação que leve em conta os sentimentos, valores morais e o exercício de uma ética da razão cordial, a qual deve ajudar na valorização da vida comunitária (revalorizando coletividades) e na formação do caráter dos indivíduos, o que a nosso ver contribui para a construção de valores e identidades mais sólidas. Aliado a isso, acreditamos que é tarefa de cada educador(a) questionar sua influência nesse contexto, buscar formas de ressignificar o papel das instituições escolares e de ajudar na construção da identidade dos(as) estudantes adolescentes.

Em vista dessa conjuntura, perguntamo-nos: 'em que medida o trabalho pedagógico de docentes de ciências que se fundamentam em conteúdos da História e Filosofia das 
Ciências pode favorecer o diálogo com o passado e minimizar a perda de vínculo com as tradições culturais que constituíram o mundo pós-moderno?'.

Discutimos a seguir a importância da abordagem em HFC para o ensino de ciências e destacamos algumas potencialidades da hermenêutica filosófica de Gadamer para embasar a sua implementação no ensino de ciências, levando-se em consideração a adolescência e o contexto atual.

\section{Contribuições da História e Filosofia das Ciências para o ensino de ciências}

Ao longo dos processos de aprender e de ensinar a aprender ciências, deparamo-nos com inúmeros obstáculos, os quais são permeados, por exemplo, pela busca do sentido ontológico desses conhecimentos, pela compreensão e resolução de problemas e pela interpretação abstrata de modelos, leis e teorias acerca dos fenômenos naturais.

Os estudos em historiografia das ciências, por exemplo, nos permitem perceber o quanto as ciências se desenvolvem dentro de uma rede de inter-relações de pessoas com o mundo que as cerca, podendo ser analisadas sob múltiplos aspectos (filosóficos, sociológicos, históricos, etc.), de modo que a busca pela sua compreensão nos exige uma formação multidisciplinar, o que atualmente se revela muito necessário, tendo em vista a influência que a atividade científica exerce em nossa cultura. Conforme aponta Condé (2017):

\footnotetext{
(...) a historiografia da ciência é um saber hibrido. Em certo sentido, o grande fascínio que essa encruzilhada oferece é, ao mesmo tempo, a sua grande dificuldade. Todo pesquisador dessa área, em alguma medida, é incompleto, por mais que sua formação seja multidisciplinar. (...) E certamente, na medida em que a ciência é uma atividade que tem uma importância central em nossa cultura, impactando-nos de diferentes e variados modos, torna-se cada vez mais necessário analisá-la a partir de múltiplos aspectos (p. 20).
}

Dessa forma, ao considerarmos, por exemplo, a complexidade da Física enquanto produto e processo, o seu ensino, quando baseado em uma abordagem histórica e permeado por discussões acerca da natureza das ciências, pode ser um importante instrumento para difundir socialmente a construção do conhecimento físico de forma efetiva e de revestir o seu estudo de significado (MATTHEWS, 1995; MOURA, 2014; ROBILOTTA, 1988).

Nesse sentido, nas últimas décadas, a HFC tem se destacado como uma importante abordagem a ser utilizada no ensino de ciências, visto que permite, por exemplo, discutir sobre a NDC, as inter-relações entre ciência, tecnologia e sociedade bem como sobre a construção do conhecimento científico, conforme aponta Moura (2014).

O propósito de fazer com que alunos e professores aprendam e ensinem não somente Ciência, mas também sobre a Ciência, tem se constituído num objetivo pretendido por um grande número de educadores, formadores e acadêmicos. (...) Neste caminho, tem se destacado a importância da História e Filosofia da Ciência 
como uma das maneiras de promover uma melhor compreensão da natureza da Ciência, à medida que seus estudos historiográficos trazem elementos que subsidiam discussões acerca da gênese do conhecimento científico e os fatores internos e externos que a influenciam (p. 32).

Aliado a isso, há autores que argumentam sobre o potencial da HFC para humanizar as ciências, melhorar a qualidade das aulas de ciências e tornar o seu ensino e aprendizado mais significativo. Roberto Martins (2006), por exemplo, concorda que o trabalho com história das ciências pode complementar o ensino comum das mesmas e nos ajudar a compreender que elas guardam uma interdependência com a cultura e a sociedade como um todo, argumentando que:

O estudo adequado de alguns episódios históricos permite compreender as interrelações entre ciência, tecnologia e sociedade, mostrando que a ciência não é uma coisa isolada de todas as outras, mas sim faz parte de um desenvolvimento histórico, de uma cultura, de um mundo humano, sofrendo influências $e$ influenciando por sua vez muitos aspectos da sociedade (MARTINS, R., 2006, p. $\mathrm{XXI})$.

Apesar desse reconhecimento de alguns pesquisadores frente à importância da HFC no ensino de ciências, devem ser levadas em consideração as dificuldades e complexidades inerentes aos seus usos na educação, as quais vão desde a seleção rigorosa do conteúdo até o reconhecimento e o trabalho com as concepções pessoais que inevitavelmente podem se manifestar nos referenciais utilizados, nos(as) estudantes e em si mesmo (FERREIRA, 2018; OLIVEIRA; DRUMMOND, 2015).

Conforme defendem Forato, Martins e Pietrocola (2011), para se construir e implementar alguma proposta efetiva para a sala de aula, levando em conta os requisitos da historiografia e da didática da ciência, precisamos reconhecer e buscar superar diferentes desafios e obstáculos. Dentre esses obstáculos, os autores destacam a incorrência em anacronismo, a inadequação da abordagem especializada para determinada faixa etária ou contexto educacional. Eles enfatizam o perigo de se fomentar concepções que reforcem o relativismo e o subjetivismo extremos, quando se critica uma visão objetiva e empirista das ciências e se reforça, por exemplo, aspectos sociais influenciando a escolha entre diferentes modelos explicativos para um fenômeno natural.

Tais tendências se tornam ainda mais preocupantes e possíveis de ocorrer quando consideramos as influências do contexto pós-moderno na educação, abrindo espaço para um negacionismo científico, conforme destacamos anteriormente. Isso exige ainda mais cautela e busca por aperfeiçoamento e aprofundamento por parte do professor que tem o interesse de incluir a HFC em sua prática pedagógica.

É necessário mediar os aspectos sociológicos e psicológicos no desenvolvimento das ciências, destacando, também, seus inúmeros critérios epistêmicos ligados à experimentação, matematização, observação, avaliação pelos pares, dentre outros (ROBILOTTA, 1988). A 
história das ciências evidencia que não há uma única concepção de ciências que pudesse ser abarcada por um único conjunto de asserções sobre sua natureza (BAGDONAS; ZANETIC; GURGEL, 2018). Conforme defendem Forato, Bagdonas e Testoni (2017), diferentes episódios históricos podem mostrar a existência de uma pluralidade metodológica nas ciências, exemplificando diferentes aspectos da natureza das ciências e servindo de embasamento para o(a) professor(a) levantar discussões e organizar o conteúdo de acordo com seu contexto educacional e objetivos formativos.

Assim, para que esse tipo de intervenção do professor possa se efetivar, aqui propomos a sua mediação através da hermenêutica filosófica de Hans-Georg Gadamer, que segundo Abadía (2011) possui um arcabouço teórico que dialoga bem com a historiografia da ciência, em especial na interpretação das relações entre o passado e o presente, argumentando que pode ajudar os(as) historiadores(as) da ciência a pensar em novas perspectivas acerca do 'presentismo', não simplesmente entendendo-o como sinônimo de 'história whig' ou 'história anacrônica'.

Em vista disso, buscando contribuir para as reflexões sobre os usos da HFC nas aulas de ciências, sua implementação e a superação de dificuldades intrínsecas à formação dos(as) adolescentes que estão inseridos no contexto escolar pós-moderno, discutiremos alguns conceitos da hermenêutica filosófica de Gadamer, conforme apresentado a seguir.

\section{Gadamer e a hermenêutica filosófica}

Ao longo da história, a palavra hermenêutica esteve ligada à interpretação de textos sagrados, jurídicos e de textos clássicos, com caráter filológico, de forma a buscar uma técnica capaz de decifrar os significados desses escritos (REALE; ANTISERI, 2008; SOUSA; GALIAZZI, 2017).

Entretanto, com o advento da ciência moderna e da sua influência nos vários setores da vida humana, surgiram algumas tentativas de fundamentar as ciências do espírito (ou humanas), de modo diferente das ciências da natureza, buscando autonomia metodológica através da hermenêutica, tal como se deu na obra do filósofo e historiador alemão Wilhelm Christian Ludwig Dilthey (1833-1911).

Esse encaminhamento de Dilthey, naquele contexto, foi importante para que, ao longo do século XX, a teoria hermenêutica adquirisse estatuto filosófico, o que se deu com os trabalhos do filósofo alemão Martin Heidegger (1889-1976), o qual concebeu a compreensão como um elemento inerente e fundante do próprio homem, atribuindo a ela uma função fenomenológica. Segundo Reale e Antiseri:

(...) foi Heidegger quem compreendeu o estatuto filosófico das concepções de Dilthey, no sentido de que viu a hermenêutica ou "o compreender" não tanto como instrumento à disposição do homem, e sim muito mais como estrutura constitutiva do Dasein, como uma dimensão intrínseca do homem. O homem cresce sobre si 
mesmo, é um novelo de "experiências". E cada nova experiência é uma experiência que nasce sobre o fundo das anteriores e as reinterpreta (REALE; ANTISERI, 2008, p. 250).

É dentro dessa concepção que um aluno de Heidegger, o filósofo alemão Hans-Georg Gadamer (1900-2002) escreveu, em 1960, a obra Verdade e Método I, a qual estabeleceu as bases do que ficou conhecido como hermenêutica filosófica, enfatizando a relação intrínseca existente entre o processo de compreensão e a historicidade do sujeito que interpreta.

Mostramos que a compreensão é menos um método através do qual a consciência histórica se aproximaria do objeto eleito para alcançar seu conhecimento objetivo do que um processo que tem como pressuposição estar dentro de um acontecer da tradição (GADAMER, 2015, p. 408).

Nesse livro, Gadamer apresenta essa compreensão (ou hermenêutica) não como uma técnica ou metodologia de interpretação de textos, mas como um processo intimamente relacionado com o sujeito que interpreta, pois a compreensão que podemos fazer de um texto científico, por exemplo, necessariamente envolve fatores como a linguagem e as préconcepções (pré-compreensões ou preconceitos) que já temos sobre o assunto, o que coloca em evidência tanto nossa constituição como seres históricos como o papel do devir em nossas interpretações.

Dessa forma, como nosso ato de interpretar está vinculado à nossa constituição histórica e, ao longo do tempo, o conhecimento humano se modifica, as alterações em nossas pré-concepções podem trazer à tona novas perspectivas sobre o assunto ao qual nos debruçamos.

Com efeito, cada interpretação se efetua à luz do que se sabe; e o que se sabe muda; no curso da história humana, mudam as perspectivas (ou conjecturas ou préjuizos) com que se olha um texto, cresce o saber sobre o "contexto" e aumenta o conhecimento sobre o homem, a natureza e a linguagem. Por isso, as mudanças, mais ou menos grandes, que ocorrem em nossa pré-compreensão podem constituir, conforme o caso, outras formas de releitura do texto, novos raios de luz lançados sobre ele, em suma, novas hipóteses interpretativas à submeter à prova (REALE; ANTISERI, 2008, p. 252).

Nesse sentido, a partir do entendimento de que nossa compreensão mantém íntima relação com a nossa historicidade, em uma parte de Verdade e Método I, Gadamer (2015) dá destaque à discussão entre razão e tradição, buscando mostrar que não há incompatibilidade entre esses conceitos, ou seja, que tradição não é o mesmo que tradicionalismo, e que reconhecer a validade das tradições culturais não é uma atitude que se opõe ao desenvolvimento do conhecimento racional das coisas, mas antes que o sustenta - o complementa. 
Assim sendo, são elementos centrais da hermenêutica filosófica de Gadamer: o reconhecimento de que o passado exerce fundamental influência na nossa compreensão do mundo, o fato de estarmos sempre inseridos em uma tradição cultural e que ela tem uma função de validade para além da fundamentação racional. Com efeito, tal hermenêutica nos coloca a possibilidade de estabelecermos uma mediação entre presente, passado e perspectivas futuras, por meio do reconhecimento do valor da tradição como fundante para o ato de compreender (SANTIAGO; MIRANDA, 2018).

Diante do exposto e levando em conta que o(a) professor(a) está sempre diante da tarefa de interpretar e mediar o conhecimento com os(as) estudantes, consideramos que a hermenêutica filosófica é um elemento muito importante no contexto que estamos tratando. Sousa e Galiazzi (2018), partindo dos estudos de Gadamer sobre tradição de linguagem, nos chamam a atenção para o reconhecimento do professor como um tipo de tradutor-intérprete da tradição histórica que abarca o conhecimento científico.

\begin{abstract}
Dentro de um processo educacional dialógico, podemos traçar elementos que posicionam o professor como tradutor-intérprete de uma tradição histórica de linguagem. Partimos da compreensão de que o professor não usará integralmente a linguagem original de um conhecimento científico no processo educativo, pois o professor se constitui como um intérprete daquele conhecimento que possui uma tradição da qual ele se torna parte por suas experiências acadêmico-profissionais. O conhecimento cientifico possui uma tradição histórica que o professor, com seus limites de compreensão, inclusive temporais, não consegue abarcar na integralidade. As exatas condições de origem da tradição de um conhecimento científico são inacessiveis ao professor que, dentro de sua finitude, consegue apenas interpretá-las linguisticamente dentro de seu próprio tempo histórico (SOUSA; GALIAZZI, 2018, p. 276).
\end{abstract}

Assim, ao reconhecermos a insuficiência do modelo de razão iluminista e da nossa historicidade para a compreensão da realidade, consideramos que essa hermenêutica vai ao encontro tanto de estudos dos críticos da pós-modernidade (os quais propõem um resgate das tradições e do sentimento de pertencimento à coletividade como forma de fortalecer as subjetividades e as identidades das pessoas, em particular dos adolescentes), como dos(as) pesquisadores(as) da historiografia das ciências (que reconhecem a rede complexa de conexões entre passado e presente, suas influências na vida dos cientistas e admitem a impossibilidade de um(a) historiador(a) estudar tudo o que ocorre a cada instante).

Ademais, o uso dessa hermenêutica permite a compreensão de fatores racionais, como os procedimentos epistêmicos experimentais e teóricos, inscritos em uma pluralidade de metodologias validadas pela comunidade ao longo da história (MARTINS, R., 1999; ROBILOTTA, 1988). Dessa forma, mesmo destacando outros fatores sociais presentes tanto na análise de episódios históricos quanto na construção dos conceitos científicos, é preciso 
levar em consideração, igualmente, os elementos considerados mais racionais neste desenvolvimento e que fazem parte dos processos ontológicos das ciências.

Aqui também é importante retomar o posicionamento da filósofa Adela Cortina frente aos valores e decisões morais humanos, que segundo a mentalidade cientificista ficam reduzidos a fatores subjetivos e irracionais mas que podem ser entendidos a partir do que ela denomina de razão cordial, a qual é condição necessária para promover a justiça e favorecer a igualdade de oportunidades entre as pessoas.

\begin{abstract}
Assim, a mentalidade cientificista, que segundo Adela Cortina é consequência do domínio da razão técnica/instrumental, ao fazer equiparar objetividade e neutralidade axiológica relega a dimensão ética para o campo do subjetivismo, do pessoal e até do irracional, afastando qualquer possibilidade de justificação racional das decisões morais. Identificando conhecimento com conhecimento científico e técnico, limita a este a possibilidade de discussão e argumentação, facto oportuna e frequentemente sublinhado pela filósofa de Valência: “(...) o cientificismo relega para a teoria e para o conhecimento cientifico toda a possivel racionalidade e objetividade, deixando as decisões morais para o âmbito subjetivo das decisões e das preferências irracionais. ". (...) Nesta linha de preocupações, não é excessivo repetir o que a filósofa espanhola pretende: trata-se de salvaguardar a ideia de que as nossas opções e decisões podem ser justificadas usando razões, escapando à prepotência e à tirania de qualquer imposição ou à arbitrariedade da ausência de critério, querendo demonstrar que o agir humano ao nível da moralidade não está refém do subjetivismo, mas é dotado de racionalidade e que esta não pode ser entendida como característica exclusiva do domínio teórico/científico do pensamento humano (PIRES, 2014, p. 61).
\end{abstract}

Nesse sentido, para destacarmos alguns pontos de ressonância entre a hermenêutica filosófica e as dificuldades de implementação da HFC no contexto escolar pós-moderno, finalizaremos com uma reflexão acerca da relação entre razão e tradição e sobre o princípio da história efeitual. Com efeito, argumentamos que o conhecimento e trabalho do(a) professor(a), por meio dessas perspectivas, pode ajudar a minimizar as concepções ligadas ao relativismo e ao subjetivismo que eventualmente vierem a se manifestar ao longo de sua prática pedagógica, principalmente no contexto atual de fake news, pós-verdade e negacionismos.

\title{
V. Indicativos da potencialidade da hermenêutica filosófica de Gadamer para mediar a implementação da HFC no ensino de ciências
}

Como vimos, os propositores da hermenêutica filosófica afirmam que o processo de compreensão de um determinado conceito ou de um fato histórico está intimamente relacionado com a historicidade do sujeito que os interpreta. Tal característica implica, por exemplo, no reconhecimento de que as nossas pré-concepções ou preconceitos influenciam na 
nossa interpretação dos fatos e de que estamos sempre inseridos em uma tradição cultural comum, a qual nos constitui e possui validade sem necessariamente precisar de uma fundamentação ou embasamento racional que a justifique.

No entanto, a hermenêutica filosófica de Hans-Gadamer não pretende colocar a tradição em contraposição à razão, mas antes propõe o reconhecimento de que elas estão inter-relacionadas e se complementam. Nesse sentido, reconhecer os próprios pressupostos ou preconceitos acerca de um tema em estudo e as influências das mudanças históricas neste estudo é uma ação importante no trabalho de interpretação de qualquer obra - e isso é obtido por meio do uso sistemático da razão. Em vista disso, é justamente a ressignificação da importância da razão que, desta vez, abarca mais fatores do que aqueles costumeiramente mais associados à técnica e ao universo científico mais restrito o fator que pode combater o negacionismo científico e as pós-verdades dos processos histórico-sociais passados ou em curso, conforme sugere Gadamer (2015):

Será verdade que achar-se imerso em tradições significa em primeiro plano estar submetido a preconceitos e limitado em sua própria liberdade? O certo não será, antes, que toda existência humana, mesmo a mais livre, está limitada e condicionada de muitas maneiras? E se isso for correto então a ideia de uma razão absoluta não representa nenhuma possibilidade para a humanidade histórica. Para nós a razão só existe como real e histórica, isto significa simplesmente: a razão não é dona de si mesma, pois está sempre referida ao dado no qual exerce sua ação (p. $367)$.

Assim, temos o conceito de história dos efeitos ou o princípio da história efeitual como um elemento central no arcabouço teórico da hermenêutica filosófica de Gadamer. Ele indica a necessidade de incluir a própria historicidade do pensar no processo de investigação sobre a história, de modo a reconhecer que, quando buscamos compreender um fenômeno histórico, já nos encontramos sob a influência dos efeitos desse fenômeno na própria história. Dessa forma, debruçar-se sobre um estudo histórico envolveria tomar como objeto de investigação tanto a realidade da história como a realidade do compreender histórico, buscando uma fusão ou união entre eles.

Um pensamento verdadeiramente histórico deve incluir sua própria historicidade em seu pensar. Só então deixará de perseguir o fantasma de um objeto histórico objeto de uma investigação que está avançando - para aprender a conhecer no objeto o diferente do próprio, conhecendo assim tanto um quanto o outro. $O$ verdadeiro objeto histórico não é um objeto, mas a unidade de um e de outro, uma relação formada tanto pela realidade da história quanto pela realidade do compreender histórico. Uma hermenêtica adequada à coisa em questão deve mostrar a realidade da história na própria compreensão. A essa exigência eu chamo de "história efeitual". Compreender é, essencialmente, um processo de história efeitual (GADAMER, 2015, p. 396). 
Nessa perspectiva, o princípio da história efeitual pode nos ajudar a perceber, por exemplo, que os efeitos de uma obra ao longo da história vão além do que o seu autor concebeu. Portanto, ao mesmo tempo em que podemos reconhecer a alteridade de um texto, também podemos nos valer do conhecimento dos seus efeitos na história para interpretarmos seu conteúdo de sentido ou conjunto de significados. Consequentemente, quanto mais antiga uma obra, maior a possibilidade de aprendermos a partir dela, pois podemos encontrar mais estudos e interpretações acerca do seu conteúdo e dos seus efeitos na história.

\begin{abstract}
(...) uma vez gerado, um texto tem vida autônoma. (...) A história dos efeitos de um texto sempre determina mais plenamente o seu sentido. E o intérprete relê o texto também à luz da história dos efeitos.

Um cientista não vê todas as consequências da teoria que criou; não as vê porque não pode vê-las, porque lhe faltam aquelas peças de saber que permitiriam sua extração; assim, não vê o desenvolvimento histórico de sua teoria. Mas o historiador da ciência (...) vê mais e melhor do que o próprio criador da teoria. Ele vê coisas que este último sequer sonhava em inserir no texto. E o historiador vê melhor a teoria porque também a vê à luz da história dos efeitos da própria teoria. $O$ que dissemos de uma teoria vale para qualquer obra humana, para qualquer texto (REALE; ANTISERI, 2008, p. 254).
\end{abstract}

Mas o que esses conceitos têm a ver com o ensino de ciências? Em que medida conhecer essas ideias pode nos ajudar a utilizar a HFC no trabalho pedagógico que desenvolvemos com os estudantes da educação básica? Esse estudo pode oferecer elementos aos professores para conduzirem tais práticas?

Em primeiro lugar, é importante ressaltar que existem pesquisas mostrando que a hermenêutica pode auxiliar na nossa compreensão do desenvolvimento do conhecimento científico e no trabalho com o ensino de ciências (ABADÍA, 2011; BOMBASSARO, 1992; SOUSA; GALIAZZI, 2018; LEIVISKÄ, 2013). Nos estudos de Bombassaro (1992), por exemplo, encontramos a proposta de que a epistemologia e a hermenêutica são atividades filosóficas indispensáveis para a nossa compreensão dos aspectos racionais e históricos que se mostram inerentes à produção do conhecimento científico.

\footnotetext{
Para que se possa compreender o conhecimento como manifestação de racionalidade e historicidade implica termos de ultrapassar a concepção fragmentária do saber, pois nem a racionalidade nem a historicidade podem ser compreendidas como assuntos exclusivos de uma disciplina especifica. Considerar o conhecimento assunto exclusivo da epistemologia não nos leva a resposta sobre a possibilidade de compreender como a racionalidade e a historicidade constituem-se elementos interdependentes e complementares. (...) Entretanto, embora não se possa descartar a epistemologia, uma nova maneira de compreender o conhecimento estaria vinculada à aceitação da atividade hermenêutica como complemento da reflexão metodológica (BOMBASSARO, 1992, p. 116).
} 
No trabalho de Leiviskä (2013), temos a argumentação de que as ações pedagógicas embasadas na hermenêutica filosófica de Gadamer podem ajudar a conscientizar os estudantes de limitações em suas concepções prévias do mundo e criar uma abertura para compreenderem, por exemplo, que nosso conhecimento atual não está completo; possuindo uma falibilidade. Dessa forma, Leiviskä acredita que podemos desenvolver nos estudantes uma visão sobre o conhecimento científico que não é dogmática.

Além disso, em Souza e Galiazzi (2017 e 2018) encontramos outras contribuições da hermenêutica filosófica de Gadamer para o ensino de ciências, tais como o desenvolvimento de uma formação de professores(as) que possibilite o reconhecimento de que a estética, a linguagem e a história perpassam nossa formação humana, o cultivo da educação como modo de compreensão de nós mesmos, de como somos no mundo e o entendimento do(a) professor(a) como tradutor-intérprete de uma tradição histórica de linguagem.

Conforme ressaltamos anteriormente, o contexto sóciocultural pós-moderno traz uma série de dificuldades para os(as) adolescentes que compõem o cenário da escola atual, os(as) quais geralmente já experimentam vários conflitos pessoais como consequência natural dessa fase da vida, a qual fomenta uma crise de identidade. Nesse sentido, em um trabalho sobre formação de professores(as), Silva (2013) argumenta que a falta de reconhecimento das tradições e o enfraquecimento do sentimento de pertencimento social se constituem como alguns dos desafios de se educar na pós-modernidade. Ademais, em um contexto do PIBID (Programa Institucional de Bolsa de Iniciação à Docência), Silva e Forato (2017) apontaram para a possibilidade do conhecimento científico fomentar no adolescente o sentimento de pertencimento histórico-cultural com a humanidade, o que entendemos ser um elemento fundamental para a construção de identidades mais estáveis e fortalecidas ao longo da adolescência.

Outra questão importante foram as tentativas de incorporar a discussão da formação do fisico nas aulas. Para tanto, a fisica foi mostrada como uma conquista da humanidade, ao longo de séculos, e que a tarefa de construção deste conhecimento ainda segue, inclusive com a necessidade de quadros para tal. Buscamos com isso fomentar o sentimento de pertencimento do adolescente a esta humanidade e, portanto, a este conhecimento. Trata-se de uma maneira - talvez pretensiosa, mas consciente - de criar um vínculo entre o adolescente, o conhecimento cientifico e a humanidade. Além disso, forçosamente explicita que as ciências podem fazer parte de seu projeto de vida profissional e, neste sentido, torna-se imperioso mostrar a vida universitária: o que faz um cientista, como estuda, etc., evitando os estereótipos (SILVA; FORATO, 2017, p. 103).

Anteriormente também comentamos que, entre os desafios para implementarmos uma abordagem em HFC no ensino de ciências, o perigo de despertar ou estimular concepções relativistas ingênuas e subjetivistas é bem sério (FORATO et al., 2011), visto que pode ser ainda mais acentuado pelo fato de guardar uma estreita relação com as condições do 
momento histórico atual, que apontam tendências à dispersão, à relativização de ideias e ao narcisismo exacerbado. Reforçando esses desafios, também reconhecemos que estamos vivendo um momento de negacionismo científico, em que vemos movimentos terraplanistas, antivacinas e de outras ideias que demonstram a ausência de uma alfabetização científica efetiva de boa parte da população.

Nesse sentido, a apresentação de uma ciência construída por diferentes homens e mulheres ao longo da história, assim como a discussão de limites de observação e de validade que envolve algumas pesquisas científicas, pode implicar em tentativas de reduzir as teorias científicas simplesmente a opiniões pessoais; como se elas pudessem prescindir de objetividade.

De modo geral, quando se afirmam os limites da observação na pesquisa científica dos fenômenos naturais, corre-se o risco de sugerir ou fomentar a falta de parâmetros objetivos. É importante haver cuidado para não incorrer ou fomentar o relativismo, levando o aluno a entender, por exemplo, que as diferentes teorias existentes para explicar um mesmo fenômeno sejam apenas meras opiniões pessoais. Desse modo, seria adequado que a forma de apresentar o conteúdo histórico permitisse problematizar a observação neutra dos fenômenos $e$ experimentos, sem, entretanto, desvalorizar a importância da observação, da evidência experimental, dos argumentos racionais e do ceticismo na construção do conhecimento cientifico (FORATO; MARTINS; PIETROCOLA, 2011, p. 47).

À luz dessas perspectivas, elencamos três argumentos que consideramos indicativos da potencialidade da hermenêutica filosófica de Gadamer para ajudar a implementar a HFC no ensino de ciências de um modo que evite (ou pelo menos minimize) o fomento de concepções relativistas ingênuas e subjetivistas ao longo do processo educativo.

- Em primeiro lugar, o entendimento de que somos seres históricos e que isso afeta diretamente o nosso processo de compreensão (Gadamer, 2015) pode ajudar o(a) educador(a) a reconhecer que, ao longo de sua prática pedagógica, tanto as características da pós-modernidade como suas pré-concepções ou preconceitos sobre o tema podem influenciar em suas intenções e atitudes. Aqui também se abre um espaço para familiarizar os(as) educandos(as) com suas próprias pré-compreensões e conscientizá-los da falibilidade do conhecimento e da finitude humana que, segundo Leiviskä (2013), são experiências que podem contribuir para o cultivo do nãodogmatismo nas ciências durante o trabalho pedagógico com os(as) estudantes. Nesse sentido, acreditamos que, quanto mais o(a) professor(a) conseguir se autoavaliar e estar ciente de suas inclinações, pré-concepções e interpretações sobre as teorias científicas e seu desenvolvimento histórico, maior será a chance de estudar e escolher trabalhar com materiais que mostram o caráter humano e sócio-histórico das ciências, sem deixar de enfatizar a estrutura coerente em que estão embasadas; 
buscando-se sempre uma abordagem lógica nas argumentações, observações, conceituações e evidências experimentais.

- Em segundo lugar, partindo do pressuposto de que o processo de compreensão acontece dentro de uma tradição cultural comum, o que implica que os conceitos de razão e tradição não são dicotômicos, mas complementares, podemos discutir, por exemplo, que o fato de Newton ter contribuído para estabelecer as bases de uma concepção mecanicista do universo não contraria a visão de mundo mágicohermética que fundamentava a sua crença de que o estudo da natureza e o estudo da religião eram indissociáveis (FORATO, 2018). Dessa forma, ao mesmo tempo em que evidenciamos a influência da tradição renascentista europeia na concepção de Newton e seus contemporâneos, mostramos o quanto o seu trabalho em Filosofia Natural foi influente para o desenvolvimento da ciência moderna, exigindo o uso sistemático de princípios matemáticos e evidências experimentais para, por exemplo, desenvolver a sua teoria da gravitação universal. Nessa perspectiva, tomando o cuidado de reconhecer suas pré-concepções e de escolher referenciais adequados para sustentar seus argumentos e levantar discussões sobre HFC, o(a) professor(a) pode ir gradualmente mostrando aos(às) estudantes a necessidade de ter fundamentação teórica, evidência experimental e argumentação lógica para tecer críticas sobre o desenvolvimento de uma teoria científica, evitando a tendência de considerar qualquer raciocínio válido e de falar "por si mesmo" - atitudes que são inerentes ao relativismo ingênuo e subjetivismo citados anteriormente.

- Em terceiro lugar, o princípio da história efeitual pode auxiliar o(a) professor(a) de ciências tanto para argumentar, por exemplo, que a Filosofia de Platão influenciou no desenvolvimento da Física de Galileu Galilei como para fundamentar a hipótese da existência de energia escura no universo sem necessariamente explicar o que a origina ou o modo como podemos nos utilizar dela. No primeiro caso, podemos observar os efeitos das obras de Platão e de Galileu Galilei na história e encontrar um conjunto de interpretações desses autores que nos servem de base para relacioná-los, tal como aparece no trabalho de Alexandre Koyré (2011), que apresenta diversos argumentos sobre a influência da filosofia platônica na construção da física galileana, enfatizando principalmente a atitude de Galileu em defender o estudo da natureza por meio do conhecimento matemático (KOYRÉ, 2011; SANTOS, 2018). Por outro lado, como as pesquisas sobre energia escura são muito recentes, carecemos de informações suficientes sobre sua natureza e os efeitos de seus estudos na história para poder falar, por exemplo, de possíveis aplicações tecnológicas. Dessa forma, no contexto apresentado, o princípio da história efeitual nos dá fundamentos para fazermos uma relação sem necessariamente relativizar (Platão-Galileu) e de justificarmos a ausência de respostas sem necessariamente incorrermos em descrédito ou subjetivismo (energia escura). 
Diante do que foi exposto, é importante salientar que encaminhamentos como o que esboçamos aqui são evidências de possibilidades de superação de alguns dos inúmeros desafios que se impõem à educação no contexto atual e particularmente no ensino de ciências. Destacamos, portanto, que assim como indicaram os anteriormente citados trabalhos de Amaral (2011) e Silva e Forato (2017), é possível criar condições educacionais capazes de despertar o sentimento de pertencimento histórico em jovens adolescentes e de fortalecer suas identidades.

Nessa perspectiva, acreditamos serem necessários maiores investimentos na formação de professores(as) e na educação básica com vistas a abarcar esses aspectos e também possibilitar o reconhecimento e vivência de uma razão cordial, que nos permita conhecer a justiça e assegurar o respeito aos direitos humanos, conforme defendido pela filósofa Adela Cortina (PIRES, 2014). Dessa forma, podemos favorecer a busca por igualdade de oportunidades e ajudar na promoção de uma educação que também leve em conta os valores morais, de modo a influenciar justamente na formação do caráter dos(as) adolescentes.

(...) a educação moral deve ajudar na formação do caráter individual. Trata-se de ajudar os jovens a modelar seu próprio caráter de tal modo que cheguem a ver a si mesmos como pessoas motivadas, desejosas de fazer planos, afeiçoadas por seus projetos de autorrealização, sentindo-se capazes de levá-los a termo, mas ao mesmo tempo conscientes de que para isso precisam contar com os outros e com um pouco de sorte. Nessa tarefa educativa torna-se imprescindivel fortalecer o autoconceito visando fomentar a autoestima, com a inevitável heteroestima que a acompanha (CORTINA; MARTINEZ, 2015, p.171, grifo dos autores).

Assim sendo, a nosso ver essa hermenêutica pode contribuir para a educação de fatores fundamentais e para ajudar a promover uma efetiva implementação da HFC no ensino de ciências, a qual também leve em consideração os aspectos da adolescência no contexto escolar atual. Nesse sentido, finalizamos essa seção fazendo alusão a uma frase presente na obra "Por que ler os clássicos?", do escritor italiano Italo Calvino (1923-1985), a qual apresenta uma consonância com o nosso trabalho e que acreditamos ser indicativa da nossa responsabilidade em preservar o patrimônio cultural da humanidade e em tentar resgatar o nosso sentido de pertencimento histórico, seja enquanto indivíduos que reconhecem sua historicidade, seja enquanto professoras e professores que se veem diante da tarefa de educar.

Os clássicos são aqueles livros que chegam até nós trazendo consigo as marcas das leituras que precederam a nossa e atrás de si os traços que deixaram na cultura ou nas culturas que atravessaram (ou mais simplesmente na linguagem ou nos costumes) (CALVINO, 2007, p. 11). 


\section{Algumas considerações}

Ao longo deste artigo, buscamos argumentar que a hermenêutica filosófica de Gadamer é um campo de estudos coerente para lidar com algumas complexidades e dificuldades inerentes à implementação da abordagem em HFC no ensino de ciências. Para tanto, apresentamos algumas características do contexto sócio-cultural pós-moderno e de adolescência que influenciam diretamente na conjuntura escolar, as quais precisam ser levadas em consideração quando almejamos promover um ensino de ciências capaz de desenvolver um senso de pertencimento histórico e cultural nos(as) estudantes.

Dentre as possibilidades, destacamos a necessidade de pesquisadores de ensino de ciências, inclusive aqueles que estudam NDC, reconhecerem as potencialidades do seu objeto de estudo contribuir para educar melhor jovens adolescentes diante dos enormes desafios da sociedade pós-moderna. Esse trabalho apontou para a importância da revalorização das tradições em detrimento da constante valorização das inovações e das coisas rápidas (que torna efêmero quaisquer vivências e, portanto, a consolidação e o fortalecimento das identidades e das subjetividades) e da atenção à possibilidade de desenvolvimento do sentimento de pertencimento dos(as) estudantes adolescentes à humanidade por meio de um dos seus bens mais preciosos: o conhecimento científico acumulado e construído ao longo de milênios, que deve ser preservado por todos e todas. Nesse sentido, resgata um possível despertar de sentido para a vida, o qual vai além da própria existência do sujeito que, por sua vez, tem aparecido mais associada à adesão às formas de consumo, às individualidades excessivas e a um sentimento de vazio existencial apontado por grande parte dos autores citados neste trabalho.

Nessa perspectiva, também destacamos a necessidade de promover uma educação moral que leve em conta os afetos, valores, senso de justiça e desejo de autorrealização nos(as) adolescentes. Além disso, entre os desafios que envolvem os usos da HFC no ensino de ciências, enfatizamos o perigo de fomentar concepções ligadas ao relativismo e o subjetivismo, pois essas tendências estão intrinsecamente relacionadas com o momento histórico atual.

Dessa forma, finalizamos com a apresentação de algumas ideias centrais da hermenêutica filosófica de Hans-Georg Gadamer e tecemos alguns argumentos acerca do seu potencial para fundamentar a implementação da HFC no ensino de ciências evitando o fomento de concepções relativistas.

Nesse sentido, aqui levantamos a necessidade de um reconhecimento de si mesmo como ser histórico, uma conscientização de suas pré-concepções ou preconceitos acerca dos temas em estudo, das influências dos mesmos em nosso processo de compreensão e uma escolha coerente de materiais antes de realizarmos alguma atividade pautada em HFC. Com isso, acreditamos ser possível construir argumentos e fomentar discussões na educação básica capazes de relacionar as teorias científicas com o contexto social de seu desenvolvimento sem correr o risco de incorrer em relativismo. Isso nos permite reconhecer as ciências como uma 
atividade humana que se desenvolve e se modifica ao longo da história ao mesmo tempo em que trabalhamos os aspectos epistêmicos específicos de cada área.

\section{Referências}

ABADÍA, O. M. Hermeneutical contributions to the history of science: Gadamer on 'presentism'. Studies in History and Philosophy of Science Part A, v. 42, n. 2, p. 372-380, 2011.

ALBUQUERQUE, A.; QUINAN, R. Crise epistemológica e teorias da conspiração: o discurso anti-ciência do canal "Professor Terra Plana". Revista Mídia e Cotidiano, v. 13, n. 3, p. 83-104, 2019.

AMARAL, M. Encontros com professores de uma escola estadual do Ensino Médio - uma escuta em que a dimensão objetiva se vê alinhavada pela subjetividade dos autores. In: AMARAL, M. (Org.). Educação, psicanálise e direito: combinações possíveis para se pensar a adolescência na atualidade. São Paulo: Casa do Psicólogo, 2006. 216p.

AMARAL, M. A estética transgressora do rap e do funk: em direção à reversão dialética da educação pública nas metrópoles brasileiras. In: AMARAL, M. G. T. do; SOUZA, M. C. C. C. de. Educação pública nas metrópoles brasileiras: impasses e novos desenlaces. Jundiaí: Paco Editorial; São Paulo: Edusp, 2011, p. 279-300.

ARIÈS, P. História social da criança e da família. 2. ed. Rio de Janeiro: LTC Editora, 1981. $224 p$.

BAGDONAS, A.; ZANETIC, J.; GURGEL, I. O maior erro de Einstein? Debatendo o papel dos erros na ciência através de um jogo didático sobre cosmologia. Caderno Brasileiro de Ensino de Física, v. 35, n. 1, p. 97-117, 2018.

BAUMAN, Z. O mal-estar da pós-modernidade. Rio de Janeiro: Jorge Zahar, 1998. 276p.

BOMBASSARO, L. C. As fronteiras da epistemologia: como se produz o conhecimento. Vozes, 1992. 144p.

BRAGA, M.; GUERRA, A.; REIS, J. C. A Física experimental numa perspectiva históricofilosófica. In: PEDUZZI, L. O. Q.; MARTINS, A. F. P.; FERREIRA, J. M. H. (Orgs.). Temas de História e Filosofia da Ciência no Ensino. Natal: EDUFRN, 2012.

CALligARIS, C. A adolescência. São Paulo: Publifolha, 2000. 88p. 
CALVINO, I. Por que ler os clássicos. 2. ed. São Paulo: Companhia das Letras, 2007. 277p.

CARVAlHO, T. A.; REIS, J. C. Diálogos entre Ciência e Arte: Uma leitura a partir da obra de Remedios Varo para um Ensino sobre as Ciências. Caderno Brasileiro de Ensino de Física, v. 37, p. 173-196, 2020.

CASTRO, R. E.; TEIXEIRA, M. R. F. Visão pós-moderna da educação e os debates de educação em ciências. Revista Litterarius. Faculdade Palotina, v. 16, n. 02, 2017, p. 1-11.

CONDÉ, M. L. L. 'Um papel para a história': o problema da historicidade da ciência. Curitiba: Editora UFPR, 2017.

CORTINA, A; MARTÍNEZ, E. Ética. Tradução: Silvana Cobucci Leite. São Paulo: Ed.6 Loyola, 2015. 176p.

DUNKER, C. Narcisismo Digital. Reinvenção da intimidade: políticas do sofrimento cotidiano. São Paulo: Ubu Editora, 2017. 320p.

FERREIRA, G. K. Reflexões sobre a natureza da ciência: configurações e intenções na formação de professores de física, 2018. 357 p. Tese (Doutorado em Educação Científica e Tecnológica) - Universidade Federal de Santa Catarina.

FORATO, T. C. M. Isaac Newton and the hidden forces in Universal Gravitation: Delimiting na Approach for teacher Training. In: PRESTES, M. E. B.; SILVA, C. C. (Org.). Teaching Science with Context Historical, Philosophical, and Sociological Approaches. 1. ed. New York / Heidelberg: Springer, 2018. v. 1, p. 293-311.

FORATO, T. C. M.; PIETROCOLA, M.; MARTINS, R. A. Historiografia e natureza da ciência na sala de aula. Caderno Brasileiro de Ensino de Física, v. 28, n. 1, p. 27-59, 2011.

FORATO, T. C. M.; BAGDONAS, A.; TESTONI, L. Episódios históricos e natureza das ciências na formação de professores. Enseñanza de las ciencias, v. extra, p. 3511-3516, 2017.

GADAMER, H. G. Verdade e Método I: Traços Fundamentais de uma hermenêutica filosófica. Petrópolis: Vozes, 2015. 631p. 
GUTIERRA, B. C. C. Adolescência, psicanálise e educação: o mestre "possível” de adolescentes. São Paulo: Avercamp, 2003.

HABERMAS, J. O discurso filosófico da modernidade: doze lições. São Paulo: Martins Fontes, 2002. 350p.

HERCULANO-HOUZEL, S. O Cérebro Adolescente: A neurociência da transformação da criança em adulto. Rio de Janeiro, 2013.

JARDIM, W.; GUERRA, A. O artigo República das Letras, Academias e Sociedades Científicas no século XVIII: a garrafa de Leiden e a ciência no ensino. Caderno Brasileiro de Ensino de Física, v. 34, p. 774-797, 2017.

KOYRÉ, A. Estudos de História do Pensamento Científico. Tradução e revisão técnica: Márcio Ramalho. 3. ed. Rio de Janeiro: Forense universitária, 2011. 434p.

LEIVISKÄ, A. Finitude, Fallibilism and Education towards Non-dogmatism: Gadamer's hermeneutics in science education. Educational Philosophy and Theory, v. 45, n. 5, p. 516$530,2013$.

LIMA, I. P. C. Lise Meitner e a Fissão Nuclear: Caminhos para uma narrativa feminista. 2019. 181p. Tese (Doutorado em Ensino, Filosofia e História das Ciências) - Programa de Pós-Graduação em Ensino, Filosofia e História das Ciências, Universidade Federal da Bahia.

LIMA, J. F. L. A morte da Pedagogia? Os fundamentos modernos da educação escolar frente aos desafios da pós-modernidade numa perspectiva histórico-filosófica. Revista Diálogo Educacional, v. 19, n. 61, p. 844-861, jul. 2019.

LIPOVETSKY, G. A era do vazio: ensaios sobre o individualismo contemporâneo. Barueri: Manole, 2005. 197p.

MARTINS, A. F. P. Natureza da Ciência no ensino de ciências: uma proposta baseada em “temas" e "questões". Caderno Brasileiro de Ensino de Física, v. 32, n. 3, p. 703-737, 2015.

MARTINS, R. A. Introdução: a história da ciência e seus usos na educação. In: SILVA, C. C. (Org.). Estudos de história e filosofia das ciências. Subsídios para aplicação no Ensino. São Paulo: Ed. Livraria da Física, 2006a. p. 3-21. 
MARTINS, R. A. O que é a ciência, do ponto de vista da epistemologia? Caderno de Metodologia e Técnica de Pesquisa, n. 9, p. 5-20, 1999.

MARTINS, R. A. Introdução: a história da ciência e seus usos na educação. In: SILVA, C. C. (Org.). Estudos de história e filosofia das ciências. Subsídios para aplicação no Ensino. São Paulo: Ed. Livraria da Física, 2006a. p. 3-21.

MARTINS, R. A. Seria possível uma história da ciência totalmente neutra, sem qualquer aspecto whig? Boletim de História e Filosofia da Biologia, v. 4, n. 3, p. 4-7, set. 2010. Disponível em: <http://www.abfhib.org/Boletim/Boletim-HFB-04-n3-Set-2009.pdf > . Acesso em: 21 mar. 2020.

MATTHEWS, M. R. História, filosofia e ensino de ciências: a tendência atual de reaproximação. Caderno Catarinense de Ensino de Física, v. 12, n. 3, p. 164-214, 1995.

MARTINS, R. A. Seria possível uma história da ciência totalmente neutra, sem qualquer aspecto whig? Boletim de História e Filosofia da Biologia, v. 4, n. 3, p. 4-7, set. 2010. Disponível em: <http://www.abfhib.org/Boletim/ Boletim-HFB-04-n3-Set-2009.pdf>. Acesso em: 21 mar. 2020.

MATTHEWS, M. R. História, filosofia e ensino de ciências: a tendência atual de reaproximação. Caderno Catarinense de Ensino de Física, v. 12, n. 3, p. 164-214, 1995.

MOURA, B. A. O que é natureza da ciência e qual sua relação com a história e filosofia da ciência? Revista Brasileira de História da Ciência, v. 7, p. 32-46, 2014.

MOURA, C. B.; GUERRA, A. Reflexões sobre o processo de construção da ciência na disciplina de química: um estudo de caso a partir da história dos modelos atômicos. Revista Electrónica de Investigación em educación em ciencias, v. 11, n. 2, p. 64-77, dez. 2016.

NOVAIS, E. L. A crise de paradigmas na escola atual: uma escola moderna em um mundo pós-moderno. Cadernos da Educação Básica, v. 1, n. 2, p. 116-133, out. 2016.

OLIVEIRA, C. J. A relação entre os problemas internalizantes e externalizantes e o bemestar psicológico na adolescência. 2018. 98p. Dissertação (Mestrado em Psicologia) Secção de Psicologia Clínica e da Saúde, Núcleo de Psicoterapia Cognitiva-Comportamental e Integrativa, Universidade de Lisboa, Faculdade de Psicologia. 
OLIVEIRA; R. D. V. L.; QUEIROZ, G. R. P. C. Conteúdos Cordiais: Química Humanizada para uma Escola sem Mordaça. São Paulo: Livraria da Física, 2017. 128p.

OLIVEIRA, W. C.; DRUMMOND, J. M. H. F. Refletindo sobre desafios à inserção didática da História e Filosofia da Ciência em oficina de formação docente. Alexandria: Revista de Educação em Ciência e Tecnologia, v. 8, n. 3, p. 151-179, 2015.

PEREIRA, A. C. A. O adolescente em desenvolvimento. São Paulo: Harbra, 2005. 160p.

PIRES, M. C. S. Justiça e cuidado em Adela Cortina: contornos da ética num mundo global. 2014. 360p. Tese (Doutorado) - Universidade de Évora, Évora, Portugal.

REALE, G.; ANTISERI, D. História da filosofia. VI. 1.ed. São Paulo: Paulus, 2008. 496p.

ROBIlotTA, M. O Cinza, O Branco e o Preto - da Relevância da História da Ciência no Ensino da Física. Caderno Catarinense de Ensino de Física, v. 5, n. especial, p. 7, 1987.

SANTIAGO, L. M.; MIRANDA, L. U. O conceito de tradição na hermenêutica filosófica de Gadamer. HYBRIS, Revista de Filosofía, v. 10, p. 43-61, 2019.

SANTOS, M. C. Experimento e Matemática na Lei da Queda dos Corpos de Galileu Galilei. 2018. 130p. Dissertação (Mestrado) - Instituto de Filosofia e Ciências Humanas, Universidade Estadual de Campinas, São Paulo.

SCHMIEDECKE, W. G.; PORTO, P. A. Uma abordagem da história da energia nuclear para a formação de professores de física. Revista Brasileira de História da Ciência, v. 7, n. 2, p. 232-241, 2014.

SILVA, J. A. Compromisso e paixão: o universal e o singular na boa escola pública. 2008. 386p. Tese (Doutorado em Educação) - Faculdade de Educação, Universidade de São Paulo, São Paulo.

SILVA, J. A. As possíveis contribuições do ensino de ciências para a identidade do Ensino Fundamental II e para a tarefa de alfabetizar. Ciência \& Educação, Bauru, v. 19, n. 4, p. 811 $821,2013$.

SILVA, J. A. Formar professores na sociedade pós-industrial: as contribuições do conceito de projeto de vida e as especificidades da docência em ciências e matemática. In: SILVA J.; KLUTH, V. Aproximações e distanciamento no ensino de ciências e matemática: questões 
de identidade da área no âmbito filosófico e institucional. São Paulo: Porto de Ideias, 2013. 69-91p.

SILVA, J.; FORATO, T. As contribuições do subprojeto Pibid-Física para a formação inicial e continuada de professores tendo em vista a tarefa de educar o adolescente em tempos de sociedade pós-industrial. In: PRADO, J. Desafios da formação inicial do docente no contexto do Pibid: experiências de formação de professores nos arrabaldes das cidades de Diadema e Guarulhos (SP). Jundiaí: Paco Editorial, 2017. 97-136p.

SILVA, J.; STOCO, S. Pibid-Física e o Estágio Curricular Supervisionado: diálogo sobre gestão dos diferentes aspectos de sequência didática na formação inicial de professores. In: Pibid-Unifesp em diálogo: trajetórias e indagações sobre práticas de formação inicial de professores. Jundiaí: Paco Editorial, 2018. 13-50p.

SILVEIRA, F. L.; PEDUZZI, L. O. Q. Três episódios de descoberta científica: da caricatura empirista a uma outra história. Caderno Brasileiro de Ensino de Física, v. 23, n. 1, p. 26-52, abr. 2006.

SOUSA, R. S.; GALIAZZI, M. C. Traços da Hermenêutica Filosófica na Educação em Ciências: Possibilidades à Educação Química. Alexandria: Revista de Educação em Ciência e Tecnologia. Florianópolis, v. 10, n. 2, p. 279-304, 2017.

SOUSA, R. S.; GALIAZZI, M. C. A tradição de linguagem em Gadamer e o professor de química como tradutor-intérprete. ACTIO: Docência em Ciências, v. 3, n. 1, p. 268-285, 2018.

VASCONCELOS, S. S.; FORATO, T. M. Niels Bohr, espectroscopia e alguns modelos atômicos no começo do século XX: um episódio histórico para a formação de professores. Caderno Brasileiro de Ensino de Física, Florianópolis, v. 35, n. 3, p. 851-887, 2018.

VASCONCELOS, E. P.; LARA, C. A. S. Movimento Antivacina: a disseminação de uma ilusão. Percurso - Anais do IV CONLUBRADEC. Curitiba. v. 4, n. 31, p. 121-124, 2019.

ZANETIC, J. Física e Arte: uma ponte entre duas culturas. Pro-Posições, v. 17, n. 1, p. 39-57, 2006. 